\title{
Author Correction: Interaction between the microbiome and TP53 in human lung cancer
}

\author{
K. Leigh Greathouse ${ }^{1,14}$, James R. White ${ }^{2}$, Ashely J. Vargas ${ }^{1}$, Valery V. Bliskovsky ${ }^{3}$, Jessica A. Beck1, \\ Natalia von Muhlinen ${ }^{1}$, Eric C. Polley ${ }^{4}$, Elise D. Bowman ${ }^{1}$, Mohammed A. Khan ${ }^{1}$, Ana I. Robles ${ }^{1}$, Tomer Cooks ${ }^{1}$, \\ Bríd M. Ryan ${ }^{1}$, Noah Padgett ${ }^{5}$, Amiran H. Dzutsev ${ }^{6}$, Giorgio Trinchieri', Marbin A. Pineda', Sven Bilke', \\ Paul S. Meltzer ${ }^{7}$, Alexis N. Hokenstad ${ }^{8}$, Tricia M. Stickrod ${ }^{9}$, Marina R. Walther-Antonio ${ }^{8,10}$, Joshua P. Earl ${ }^{11}$, \\ Joshua C. Mell ${ }^{11}$, Jaroslaw E. Krol ${ }^{11}$, Sergey V. Balashov ${ }^{11}$, Archana S. Bhat ${ }^{11}$, Garth D. Ehrlich ${ }^{11}$, Alex Valm ${ }^{12}$, \\ Clayton Deming ${ }^{12}$, Sean Conlan ${ }^{12}$, Julia Oh ${ }^{13}$, Julie A. Segre ${ }^{12}$ and Curtis C. Harris ${ }^{1 *}$
}

\section{Author Correction to: Genome Biol https://doi.org/10.1186/s13059-018-1501-6}

Following publication of the original paper [1], the authors submitted a new Additional file 5 to replace the one containing formatting issues. The updated Additional file 5 is published in this correction.

\section{Supplementary information}

Supplementary information accompanies this paper at https://doi.org/10. 1186/s13059-020-01961-0.

Additional file 5. Clinical metadata and OTUs for NCI-MD samples.

\begin{abstract}
Author details
'Laboratory of Human Carcinogenesis, Center for Cancer, Research, National Cancer Institute, National Institutes of Health, 37 Convent Dr., Rm 3068A, MSC 4258, Bethesda, MD 20892-4258, USA. ${ }^{2}$ Resphera Biosciences, Baltimore, MD 21231, USA. ${ }^{3}$ Center for Cancer Research Genomics Core, National Cancer Institute, National Institutes of Health, Bethesda, MD 20892, USA. ${ }^{4}$ Division of Biomedical Statistics and Informatics, Mayo Clinic, Rochester, MN 55905, USA. ${ }^{5}$ Department of Educational Psychology, Baylor University, Waco, TX 97346, USA. 'Laboratory of Experimental Immunology, Center for Cancer Research, National Cancer Institute, National Institutes of Health, Bethesda, MD 20892, USA. 'Genetics Branch, Center for Cancer Research, National Cancer Institute, National Institutes of Health Bethesda, Bethesda, MD 20892, USA. ${ }^{8}$ Department of Obstetrics and Gynecology, Mayo Clinic, Rochester, MN, USA. ${ }^{9}$ Microbiome Laboratory, Mayo Clinic, Rochester, MN 55905, USA. ${ }^{10}$ Department of Surgery, Mayo Clinic, Rochester, MN 55905, USA.

${ }^{11}$ Department of Microbiology and Immunology, Center for Genomic Sciences, Institute of Molecular Medicine and Infectious Disease, Drexel
\end{abstract}

The original article can be found online at https://doi.org/10.1186/s13059018-1501-6

* Correspondence: curtis_harris@nih.gov

${ }^{1}$ Laboratory of Human Carcinogenesis, Center for Cancer, Research, National Cancer Institute, National Institutes of Health, 37 Convent Dr., Rm 3068A, MSC 4258, Bethesda, MD 20892-4258, USA

Full list of author information is available at the end of the article
University College of Medicine, Philadelphia, PA 19129, USA. ${ }^{12}$ National Human Genome Research Institute, National Institutes of Health, Bethesda, MD 20892, USA. ${ }^{13}$ Jackson Laboratory, Framingham, CT 06032, USA. ${ }^{14}$ Present Address: Nutrition Sciences, Baylor University, Waco, TX 97346, USA.

Published online: 20 February 2020

Reference

1. Greathouse KL, White JR, Vargas AJ, et al. Interaction between the microbiome and TP53 in human lung cancer. Genome Biol. 2018;19:123. https://doi.org/10.1186/s13059-018-1501-6.

\section{Publisher's Note}

Springer Nature remains neutral with regard to jurisdictional claims in published maps and institutional affiliations.

(c) The Author(s). 2020 Open Access This article is distributed under the terms of the Creative Commons Attribution 4.0 International License (http://creativecommons.org/licenses/by/4.0/), which permits unrestricted use, distribution, and reproduction in any medium, provided you give appropriate credit to the original author(s) and the source, provide a link to the Creative Commons license, and indicate if changes were made. The Creative Commons Public Domain Dedication waiver (http://creativecommons.org/publicdomain/zero/1.0/) applies to the data made available in this article, unless otherwise stated. 